\title{
The Mitochondrion: The Prisoner of a False Origin and The Victim of Wrong Theories
}

\author{
Dr. Othman Salim Hussein Al-Fleesy ${ }^{* 1}$

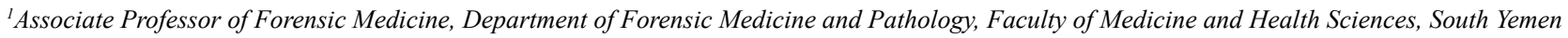

"Corresponding author: Othman Salim Hussein Al-Fleesy, Associate Professor of Forensic Medicine, Department of Forensic Medicine and Pathology, Faculty of Medicine and Health Sciences, Aden University, South Yemen, Tel: 00967 770548026, 0067 735712125, E-mail: alfleesy2001@yahoo.com

Received Date: $12^{\text {th }}$ December2017

Accepted Date: $19^{\text {th }}$ December 2017

Published Date: $23^{\text {rd }}$ December 2017

\section{Introduction}

Decades after the discovery of mitochondria. A flooding of researches and studies were gushed and published, raising a hot debate and controversy about mtDNA and its relation to evolution and origin of human kind. During my review of literature in concern to mtDNA and evolutionary matters, I found tens of theories and hypotheses were proposed; but they have contradicted each other, not only that but a number of scientists have contradicted themselves in the same research .my study seems to be important because it for the first time- since the discovery of the mitochondria and studies of the evolution and ancestry- determines the mistakes and wrong theories clearly, and proposed a new suggestion.

\section{What did The Scientists Write about Mitochondria?}

Mitochondria are still mysterious to researchers, and occupy a central position in the biology of cells and evolutionary studies.

In text books and studies, the human biologists had written that the human mitochondrial genome is a circular DNA molecule of about 16 kilo bases. It encodes 37 genes. One mitochondrion can contain two to ten copies of its DNA. Mitochondrion found in the cytoplasm of almost all eukaryotic cells (cells with clearly defined nuclei), the primary function of which is to generate large quantities of energy in the form of adenosine tri phosphate (ATP).The popular term "powerhouse of the cell" was coined by Philip Siekevitz in 1957.

\section{The origin of Mitochondria}

The origin of mitochondria has been the subject of controversy. Since its discovery up-to-date, there are two famous hypotheses about the origin of mitochondria. I put here the popular and the most accepted one to the scientists.
Citation: Othman S (2017) The Mitochondrion: The Prisoner of a False Origin and The Victim of Wrong Theories. Enliven: J Genet Mol Cell Biol 4(2): 002 .

Copyright: @ 2017 Othman Salim Hussein Al-Fleesy. This is an Open Access article published and distributed under the terms of the Creative Commons Attribution License, that permits unrestricted use, distribution and reproduction in any medium, provided the original author and source are credited.

\section{Endosymbiotic Hypothesis}

The Endosymbiotic hypothesis suggests that mitochondria were originally prokaryotic cells, capable of implementing oxidative mechanisms that were not possible for eukaryotic cells; they became endosymbionts living inside the eukaryote. The endosymbiotic hypothesis suggests that mitochondria descended from bacteria that somehow survived endocytosis by another cell, and became incorporated into the cytoplasm. The endosymbiotic relationship of mitochondria with their host cells was popularized. In the 1970s by the late Dr. Lynn Margulis Was called the "serial endosymbiosis theory." the serial endosymbiosis theory for the origin of eukaryotic cells seemed reasonable to evolutionists. Because, mitochondria are thought by evolutionist - to have originated from an ancient symbiosis that resulted when a nucleated cell engulfed an aerobic prokaryote. The stories of mitochondrial evolution and ancestral bacteria have remained controversial.

\section{What are the Questions, Mistakes and Matters of Controversy} Regarding Mitochondria?

The scientists had raised a number of questions regarding the origin of mitochondria, whether mitDNA was inherited maternally or paternally? , Is mtDNA restricted to oocyte only, or may be found in sperm? How could we trace back the ancestry with mitochondria, Is there recombination taking place between Paternal and maternal mtDNA ?...etc. It sounds good in theory to speak a lot about the biosymbiosis theory and evolution, but to Accept this, you will miss the actual facts and you will tell an entirely different story of mitochondria. Scientific papers were contained a number of mistakes and wrong theories. 
The Mistakes of The Scientists could be Summarized as follows:

\subsection{The biosymbiosis theory (the illogical theory).}

No one could imagine that the scientists in the 21 st century still believe that mitochondrion was originated from bacteria after this process (biosymbiosis). One of the scientists wrote:

Difficulties for an endosymbiotic origin include the necessity of presuming that mitochondria arose at least 2 billion years ago. How could this happen?. Who had calculated this number of years, and who could believe it? Remember if we had rejected the theory of evolution from a monkey, how can we accept this theory? which Stated that our cells or gametes and chromosomes originated from bacteria?. This is not illogic and unrealistic only; but it is a funny assumption and never have respected the humans' minds.

\section{Mutation}

Mutation is defined as the changing of the structure of a gene, resulting in a variant form that may be transmitted to subsequent generations, caused by the alteration of single base units in DNA, or the deletion, insertion, or rearrangement of larger sections of genes or chromosomes. Many scientists, undoubtedly, use this term (mutation)to justify their failure when they could not interpret or solve certain diseases, disorders or phenomena. etc. Certainly, if the scientists get rid of this wrong way of justification and interpretation and do not resort to this term (mutation) in the places of failure and try again and again, inevitably, they will arrive and succeed and can achieve some successful results. Please look to this statement: Mitochondrial DNA appears to mutate much faster than expected, prompting new DNA. How could this take place and how could they measure this speed?

\section{Random, Stochastic and Accidental Terms}

These terms, are used by scientists, who do not believe that the creation is controlled by the creator (the GOD), and even this ( chance) is given only to those who work hardly. Was the falling of an apple on Newton's head accidental or random?, Because many apples fell on the heads of many people, but no one responded to this light hit, except Newton had asked himself, why?, because others, quickly, ate the fallen apples. You have to remember that, the accidental is given only to those who deserve it. Do you think the bulb of Addison and the Vimto-Second of Ahmed Zwail were accidental? Those who think so, they are out of the scientific circle.

Disintegration of the Midpiece and the Tail of The Sperm after Fertilization

The scientists wrote: Mitochondria in the sperm from the father were presumed to be destroyed immediately after fertilization. Other wrote: the tail wiggles after the entrance of the head inside the ovum and the separation of the midpiece and tail. This assumption had reminded me with orchid after cutting their tails. Did sperm's tail suffer from pain?

\section{Paternal Leakage}

This is the last suggestion proposed by scientists. It is another impossible way. Only scientists turned all faces, trying with preconceived thoughts, but with no success.

\section{Discussion}

During my review of literature, there were contradictory data were found, the scientists were rotating around a number of points, either support or against.

The researchers forwarded a number of wrong opinions and ideas as follows

Inheritance: Is it Maternal, paternal or both?

Mitochondrial DNA (mtDNA) is generally assumed to be inherited exclusively from the mother only, and inherited to both sons and daughters.

While others said there is mitochondrial DNA in the sperm (paternal), but it is destroyed at fertilization period. That's why the scientists study paternal line only by tracing back Y chromosome. Other scientists wrote the sperm contains a single mitochondrion in the head. Kaneda et al. (1995); Cummins et al. (1997), forwarded that human mtDNA strictly derives from maternal inheritance. Some scientists rejected maternal inheritance hypothesis. Others stated that mitochondria is found in paternal cells but they are few in number. Others have claimed evidence of paternal transmission (Gyllensten et al 1991).In human mitochondrial genetics, there is debate over whether or not paternal mtDNA transmission is possible. Many studies hold that paternal mtDNA is never transmitted to offspring. While scientists still insist that mtDNA is inherited from the maternal side only (Giles et al., 1980).

- Again, there is no consensus about mitochondrial DNA inheritance and researchers contradict each other with different results and hypothesis. One factor remains constant that if this true ; the mtDNA will not altered at all it would remain intact(unchanged) through the female line. In fact, the misconception that all mtDNA inheritance must be maternal and there is no paternal mitochondria had paralyzed the vital studies and a vivid speculation.

\section{Recombination}

Over more than three decades, there has been a considerable debate as to whether there is recombination in human mtDNA. The literature is not clear in this point, and there is no certain opinion concerning recombination. Genetecists claimed that mtDNA is inherited maternally and does not recombine. Several recent papers, however, have suggested that elements of mtDNA may sometimes be inherited from the father. This hypothesis is based on evidence that mtDNA may undergo recombination.

Sutorsky et al. (2000) said that there is no evidence for recombination. While Krayspeig et al. (2004) claimed that there has been recombination between paternal and maternal mitochondria.

There is no consensus about mitochondrial DNA recombination and researchers contradict each other with different results and hypothesis.

\section{Presence in Somatic Cell}

Literature contained data that most mammalian somatic cells contain between 102 and 104 copies of mtDNA. Human oocytes contain an average of $200000 \mathrm{mtDNA}$ copies and we have shown that the increase of mtDNA copy numbers in these cells is correlated with their fertilizability (Reynier et al., 2001).They added mitochondria affect all aspects of mammalian reproduction, including oocyte maturation, fertilization and embryonic development. Again and again, there is no consensus about mitochondrial DNA presence in somatic cells for both male and female and researchers contradict each other with different results and hypothesis. 
Studies mentioned there are Mitochondrial fusion and division by binary fission, similar to bacterial cell division and they wrote:mitochondria must be duplicated during cell cycle.

This division and segregation process must be tightly controlled so that each daughter cell receives at least one mitochondrion. It is still unclear to what extent mitochondria within a cell are able to fuse and exchange contents (Legros F, et al. (2002). In concern to the number of mtDNA, some researchers mentioned that others stated there are billions of mitochondria in cytoplasm. Human egg contains one mit. Finally I can say, certainly, no consensus about any point, I have mentioned in this review, even the point of maternal inheritance of the mitochondria which seems to have a high percentage of agreement, there were some scientists opposed this complete agreement. This indicates, the confusion and the gap presents in their studies. There is no consensus about mitochondrial DNA number, fusion and division and researchers contradict each other with different results and hypothesis.

\section{Alfleesy Suggestion}

If it is true that : if the sperm's mitochondria disappear immediately after fertilization (as the scientists had mentioned in their researches with certainty) , it could be suggested that only the paternalX sperm's mitochondria is found in the fertilized cell, while there is no paternal Y sperm's mitochondria at all , in the fertilized cell. In other words, male sperm which has $\mathrm{Y}$ chromosome has no mitochondria. And the other male $\mathrm{X}$ chromosome (sperm) has mitochondria. If further future study confirm these observations, certainly , the mystery and the puzzle of unknown sperm now it is clear and the gap in old researches and studies now is filled and the solution with proposed logical and scientific interpretation.

Based on the previous studies of the scientists and their wrong assumptions, theories, contradictions, and on certain facts and on the following points:

1-The mitochondrion is originating and growing with the same manner of creation and growth of oocyte in the ovary (from the primary follicle up to mature ovum).

2-There is paternal inheritance and transmission of mtDNA via male $\mathrm{X}$ sperm only. While Y sperm has no mitochondria. The mitochondrion is located in the head of the sperm.

3- According to the documented facts in literature and the diagnosis of geneticists and embryologists, for the cases of genetic disorders as Turner syndrome carrying (XO) chromosomes, and other fetuses carrying (YO) chromosomes, and they had found in practical ground that Turner syndrome (OX) could survive, while (YO) fetus aborted and died, this indicating that male $(\mathrm{X})$ sperm must have mitochondria that is why the baby remains alive(survive), while (YO ) fetuses aborted and die quickly, because it has no mitochondria, to supply its growth and muturation.

4-It is well known that in an in vitro fertilization (IVF) and Intracytoplasmic sperm injection (ICSI), for the treatment to help women - and their husbands (partners) - conceive a child.

ICSI only needs one sperm, which is injected directly into the egg. And as part of the ICSI procedure, the embryologist $\mathrm{s}$ or specialists in gynecology and obstetrics in some cases and conditions (low motility of sperm) they break (cut) the head (decapitation) using the head only, as they declared that 1-The mitochondrion is originating and growing with the same manner of creation and growth of oocyte in the ovary (from the primary follicle up to mature ovum).

2-There is paternal inheritance and transmission of mtDNA via male $\mathrm{X}$ sperm only. While Y sperm has no mitochondria. The mitochondrion is located in the head of the sperm.

3- According to the documented facts in literature and the diagnosis of geneticists and embryologists, for the cases of genetic disorders as Turner syndrome carrying (XO) chromosomes, and other fetuses carrying (YO) chromosomes, and they had found in practical ground that Turner syndrome (OX) could survive, while (YO) fetus aborted and died, this indicating that male $(\mathrm{X})$ sperm must have mitochondria that is why the baby remains alive(survive), while (YO) fetuses aborted and die quickly, because it has no mitochondria , to supply its growth and muturation.

4-It is well known that in an in vitro fertilization (IVF) and Intracytoplasmic sperm injection (ICSI), for the treatment to help women - and their husbands (partners) - conceive a child.

ICSI only needs one sperm, which is injected directly into the egg. And as part of the ICSI procedure, the embryologist s or specialists in gynecology and obstetrics in some cases and conditions (low motility of sperm) they break (cut) the head (decapitation) using the head only, as they declared that no midpiece and tail of sperm is found at fertilization.

5-There is increasing evidence suggests that mitochondria derived ATP is not crucial for sperm motility and that glycolysis may be the main ATP supplier for this particular aspect of sperm function .May male Y sperm is supplied by this type of energy, because of the absence of mitochondria.

Based on the previous points (1-5) and on studies of the scientists and their wrong assumptions, theories, contradictions, and on known facts I wish to suggest the following

1-Paternal Y sperm has no mitochondria at all (pure maleness-masculinity).

2-paternal X-sperm has mtDNA located in its head.

3-female oocyte (X chromosome) has mtDNA (pure femaleness-femininity).

4-The mothers transmit their mtDNA (maternally) to both daughters and sons.

5-The fathers transmit their mtDNA (paternally) to their daughters only.

6-Son can trace back his grandfather and grand grandfather up to Adam (the father of human kind) via Y chromosome. I have an article - still not completed - discussing this point and discussing the wrong theory of Rebecca can and her African origin theory.

7-Daughter can trace her grandmother and grand grandmother up to Eve(the mother of human kind), and she can also trace back her grandfather and grand grandfather up to Adam by mtDNA, taking into consideration that daughters could reach to Adam or their grandfathers via Eve's mtDNAto end up to Adam. Because daughters who had missed (loss) their fathers how could they trace, and what can they do? I have an article - still not completed - discussing this point and discussing the wrong theory of Rebecca cann and her African origin theory. 
8-If paternal (Y) sperm fertilizes an ovum, its (ovum) mitochondria only for energy supplies, and other growth functions.

9-Paternal (X) sperm's mitochondria with maternal ovum (X maternal mitochondria), this mating meeting leads to recombination (fusion and division).

\section{Conclusion}

Despite the efforts of scientists to uncover the mysterious of mitochondria, many mistakes in science should be corrected, re-evaluated or rejected and discarded from the pages of researches and text books as soon as possible in order to return to right path. Because all these mistakes were being done by scientists. Who had accepted all proposed theories without thinking. Who could believe the assumptions concerning the total loss of the paternal mtDNA at fertilization, disintegrating and decomposing of the sperm tail immediately and then it is discarded. As we believe ( with no doubt), that the ovum was created by self-programmed system and controlled by the creator ( the God), so the creation of mitochondria follow the same way and process of creation of oocytes gametes (ovum and sperm).it is normal to find mitochondria In somatic cell of both son and daughter but with different percentages. Inheritance never occurring with only paternal set or maternal sets of chromosomes. They must gathering together male and female, maternal and paternal meeting and mating. There must be a couple and pair mating. (alfleesy 2017).

The missing link and the unique gap in the literature, which no scientist had discussed or forwarded solution before, is that there is a paternal (X) sperm's mitochondria and no mitochondria in a paternal (Y) sperm . The scientists, evolutionists and geneticists in need to admit, honestly that their speculations and hypotheses have failed to interpret mitDNA dilemma. Because some of their theories were lacking a real scientific ground.

Finally, we must not pretend falsely and claimed that we have discovered and invented falsely as the Korean scientist did and had announced that he cloned human embryo (alfleesy 2016). Ethically the researchers must went to admit to this failure, that these results and theories never answered their questions or solved their problems.

The time has come to start correcting the mistakes and the erroneous hypotheses and theories $\mathrm{s}$ that led to greater errors and this wrong information, currently, are teaching in the schools, institutions and medical faculties all over the world, putting our science within our limits, facilities and possibilities. Lastly if further experiments confirm these observations, this would provide an opportunity for studying these topics thoroughly and will open new doors for further experiments.

\section{References}

1. Cummins JM, Kishikawa H, Mehmet D, Yanagimachi R (1999) Fate of genetically marked mitochondrial DNA from spermatocytes microinjected into mouse zygotes. Zygote 7:151-156.

2. Cummins JM (2000) Fertilization and elimination of the paternal mitochondrial genome. Hum Reprod 2: 92-101.

3. othman Alfleesy (2017) A One - Step Meiosis of Human Chromosomes with Rearrangement of Genes, No Breakage and No Crossing Over of Chromatids. European J Biomed Pharma Sci 4: 109-114.
4. Othman Salim Hussein Al-Fleesy (2016) Human Being Cloning a False Claim and a Fabricated Results. Int J cell Sci \& molbiol 1: (2).

5. Eyre-Walker A, Awadalla P (2001) Does human mtDNA recombine?. J Mol Evol 53: 430-435.

6. Cann RL (2001) Genetic clues to dispersal of human populations: Retracing the past from the present. Science. 291:1742-1748.

7. Enriquez JA, Cabezas-Herrera J, Bayona-Bafaluy MP, Attardi G (2000) Very rare complementation between mitochondria carrying different mitochondrial DNA mutations points to intrinsic genetic autonomy of the organelles in cultured human cells. J Biol Chem 275: 11207-11215.

8. Yevgenya Kraytsberg, Marianne Schwartz, Timothy A. Brown, Konstantin Ebralidse, Wolfram S. Kunz ,et al (2004) Recombination of human mitochondrial DNA. Science 304: 981.

9. Othman Salim Hussein Al-Fleesy (2017) Why Have the Scientists Accepted the Illogical Proposal of Zuckerman for 60 Years? J Mol Biomark Diagn 8: 1000331.

10. Piganeau G, Eyre-Walker A (2004) A reanalysis of the indirect evidence for recombination in human mitochondrial DNA. Heredity 92: 282288.

11. Satoh M, Kuroiwa T (1991) Organization of multiple nucleoids and DNA molecules in mitochondria of human cells. Exp Cell Res 196: $137-140$

12. C Wiuf (2001) Recombination in Human Mitochondrial DNA, GENETICS 159: 2 749-756.

13. Blok RB, Gook DA, Thorburn DR, Dahl HH (1997) Skewed segregation of the mtDNAnt 8993 (T-->G) mutation in human oocytes. Am J Hum Genet 60: 1495-501.

14. Danan C, Sternberg D, Van Steirteghem A, Cazeneuve C, Duquesnoy P, et al (1999) Evaluation of parental mitochondrial inheritance in neonates born after intracytoplasmic sperm injection. Am J Hum Genet 65: 463-473

15. Eyre-Walker A, Smith NH, Smith JM (1999) How clonal are human mitochondria?. Proc Biol Sci 266: 477-483.

16. Folgero T, Bertheussen K, Lindal S, Torbergsen T, Oian P (1993) Mitochondrial disease and reduced sperm motility. Hum Repro 8: 1863-1868.

17. Legros F, Lombès A, Frachon P, Rojo M (2002) Mitochondrial fusion in human cells is efficient, requires the inner membrane potential, and is mediated by mitofusins. Mol Biol cell 13: 4343-4354.

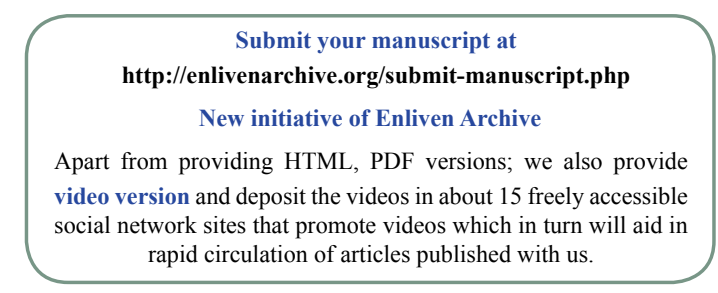

